This item was submitted to Loughborough's Research Repository by the author.

Items in Figshare are protected by copyright, with all rights reserved, unless otherwise indicated.

\title{
A qualitative study exploring how city bus drivers manage sleepiness and
}

\section{fatigue}

\section{PLEASE CITE THE PUBLISHED VERSION}

https://doi.org/10.1080/07420528.2020.1812623

\section{PUBLISHER}

Taylor \& Francis

\section{VERSION}

AM (Accepted Manuscript)

\section{PUBLISHER STATEMENT}

This is an Accepted Manuscript of an article published by Taylor \& Francis in Chronobiology International on 1 September 2020, available online: http://www.tandfonline.com/10.1080/07420528.2020.1812623.

\section{LICENCE}

CC BY-NC-ND 4.0

\section{REPOSITORY RECORD}

Pilkington-Cheney, Fran, Ashleigh Filtness, and Cheryl Haslam. 2020. "A Qualitative Study Exploring How City Bus Drivers Manage Sleepiness and Fatigue”. Loughborough University. https://hdl.handle.net/2134/12871616.v1. 
Selected Proceeding: Shiftwork 2019

\section{A qualitative study exploring how city bus drivers}

\section{manage sleepiness and fatigue.}

Fran Pilkington-Cheney ${ }^{\mathrm{a} *}$, A. J. Filtness ${ }^{\mathrm{a}}$, and C. Haslam ${ }^{\mathrm{b}}$

${ }^{a}$ Transport Safety Research Centre, School of Design \& Creative Arts, Loughborough

University, Loughborough, UK; ${ }^{\mathrm{b}}$ School of Sport, Exercise \& Health Sciences,

Loughborough University, Loughborough, UK.

ORCID numbers: FPC 0000-0001-8043-3137, AJF 0000-0001-7357-0344, CH 0000-00034899-9856

*Corresponding author:

Fran Pilkington-Cheney

Transport Safety Research Centre, School of Design and Creative Arts, Loughborough University, Leicestershire, LE11 3TU, UK

Email: f.e.pilkington-cheney@1boro.ac.uk

Funding: This work was supported by Transport for London [grant number 94050].

Declarations of interest: The authors report no conflict of interest

Word count: 6734 (including acknowledgements, excluding abstract) 


\section{Abstract}

Sleepiness is an important consideration for workplace safety, especially in relation to shift work. There is limited understanding of how practical applications of countermeasures are used to manage sleepiness in a professional setting. One under researched group is city bus drivers. This qualitative study investigated the use of individual sleepiness countermeasures within a sample of city bus drivers. Nine semistructured focus groups were convened to explore the broader experience and management of sleepiness $(n=62$, largest proportion aged 45-54 y, mean bus driving experience $13.3 \mathrm{y}$ ). The conversations of the focus groups were audio recorded (total: $682 \mathrm{~min}$ ) and transcribed anonymously verbatim. Discussions specifically relating to personal countermeasure use were isolated from the original transcripts, creating nine new transcripts for a targeted analysis on the topic of individual countermeasure use. Thematic analysis identified two main themes: (1) strategies used to counteract sleepiness and (2) barriers to individual countermeasure use, each with several subthemes. A variety of countermeasures were used, including strategies with limited potential for counteracting sleepiness, such as opening a window, drinking water, talking, stretching, and consuming forms of sugar. Workplace restrictions, such as access to facilities, limitations of food/drink consumption, and tight schedules, were the strongest influences on countermeasure choice. It is important that bus drivers have access to, and are aware of the effectiveness of, countermeasures to manage sleepiness during shift work. It is vital that the actions of drivers and shift workers are better understood in the planning of organizational countermeasures.

Keywords: bus driver, sleepiness, fatigue, countermeasures, focus groups 


\section{Introduction}

Sleepiness and fatigue can impair workplace safety and can result in an increase in injuries, accidents, and other incidents (Wagstaff \& Lie 2011). Within industry, the terms sleepiness and fatigue are often used interchangeably and can relate to both the physiological urge to fall asleep caused by lack of or disturbed sleep and the body's natural circadian rhythms, defined within the literature as sleepiness (Dement \& Carskadon 1982), or in relation to requiring a break from a task or activity due to under or over workload, defined within in the literature as fatigue (May \& Baldwin 2009). While it is recognised that sleepiness and fatigue are interlinked as depicted in Figure 1, the focus of this research is on sleepiness or sleepinessrelated fatigue, rather than task-related fatigue, and the use of countermeasures that aim to act on the circadian low or counteract sleep loss and increased pressure to sleep.

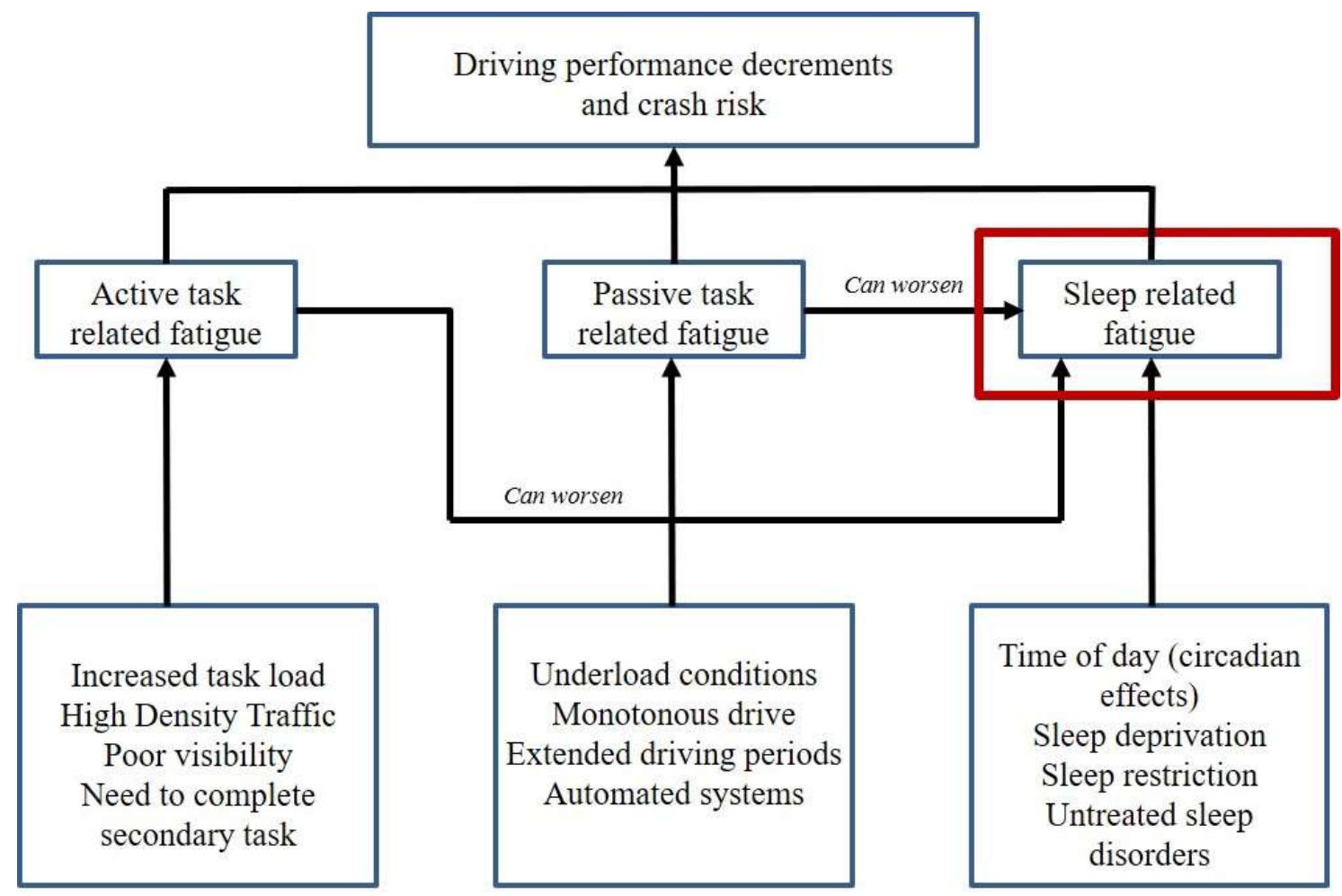

Figure 1. Schematic representation of the factors influencing driver fatigue, sleepiness, driving performance, and crash risk. Adapted from May and Baldwin (2009). 
Sleepiness is prevalent in shift workers due to a combination of factors, such as long working hours, working during circadian lows, and irregular shift patterns and start times (Gander et al. 2011). The transportation industry often utilizes shiftwork to sustain 24/7 operations, requiring individuals to be alert and efficient at times of reduced alertness. In terms of professional driving, certain aspects of the occupation can be additional risk factors for sleepiness, including sedentary working, long driving hours requiring constant attention and vigilance, changing shift patterns (Chaiard et al. 2019; Öz et al. 2010), as well as unrealistic scheduling (Biggs et al. 2009). Driving when sleepy can have severe consequences and is associated with increased crash risk (Bioulac et al. 2017), with sleepiness contributing to approximately $15 \%-30 \%$ of road traffic crashes globally (Connor et al. 2002; Horne \& Reyner 1995; Phillip et al. 2014). Although it may be thought that professional drivers are more capable of staying awake and alert compared to non-professional drivers, this is not the case (Anund et al. 2018). Within a 12-month period, 38\% of professional drivers reported experiencing sleepiness at least once a week, and $45 \%$ of drivers reported nodding off whilst driving (Friswell \& Williamson 2008).

The majority of previous driver sleepiness research has focused on private car drivers (Åkerstedt et al. 2013) or truck drivers (Pylkkönen et al. 2015, 2018), with comparatively little research on bus drivers. The limited research on bus drivers has focused on quantifying the issue, suggesting that driver sleepiness is a problem, with approximately $20 \%$ of city bus drivers regularly fighting to stay awake while driving (Anund et al. 2016; Miller et al. 2020). It was also reported that $12 \%$ of drivers had fallen asleep at the wheel at least once per month, and between $7 \%$ and $8 \%$ of drivers reported being involved in an accident or a near miss due to sleepiness (Vennelle et al. 2010). Bus driver sleepiness is not solely a European issue. In line with previous reported findings, a Peruvian study found $74 \%$ of bus drivers experienced sleepiness whilst driving the bus, with $29 \%$ of drivers having an accident or near 
miss and 36\% admitting to falling asleep while driving the bus (Deza-Becerra et al. 2017). Conversely, very little is known about the perceptions of bus drivers about sleepiness. One exception is the focus-group study by Biggs et al. (2009). It explored work and environmental factors that might cause fatigue in city bus drivers, identifying nine important factors, many of which are common within shift work settings, e.g., support from management, turnaround and shift irregularity, extended shift cycles, and extended commute times. However, several factors were specific to public transport drivers, such as interaction with passengers, cabin ergonomics, tight route schedules, and ticketing and related issues, highlighting the additional complexities bus drivers may face in relation to fatigue and sleepiness. Despite having received less attention, the research indicates that sleepiness is a major issue for city bus drivers; however, it is not clear how drivers manage their sleepiness on a day-to-day basis.

The management of occupational sleepiness is likely to involve the use of countermeasures. Countermeasures can be utilised to alleviate sleepiness and reduce the likelihood of having a sleep-related crash (Cummings et al. 2001). As presented in Figure 1, several factors can contribute to fatigue and sleepiness, which may require different and distinct approaches (May \& Baldwin 2009). Broadly speaking, there are two main initiators of countermeasures: occupational, such as company led fatigue management, and individual, which is what an individual can do to manage their sleepiness. In terms of the management of sleepiness from an occupational point of view, regulations can be put in place to specify required maximum shift and minimum break durations. However, many factors implemented as part of organizational countermeasures, e.g., scheduling, education and training, are out of the control of the drivers themselves. Drivers may, however, be able to implement individual countermeasures to alleviate sleepiness, e.g., using caffeine or napping strategies. This research focuses specifically on individual countermeasures that bus drivers employ to 
increase alertness or counteract sleepiness, rather than higher level company fatigue management, or task-related fatigue.

Strategies individuals may use to counteract sleepiness can have varying degrees of effectiveness. Effective countermeasures are defined as those that have been shown to objectively alleviate sleepiness, whereas ineffective countermeasures are those strategies that have no, or limited objective evidence of a sleepiness-alleviating effect. Strategically, effective strategies include not driving at night or following inadequate sleep; however, this is generally unrealistic in terms of shift work and professional driving. One of the most effective ways to alleviate sleepiness is by taking a 15-20 min nap, which has been shown to reduce physiological and subjective sleepiness, and improve driving performance (Horne \& Reyner 1996; Watling et al. 2014). Caffeine is another important countermeasure, and effectively increases alertness and improves performance after 20 min (De Valck \& Cluydts 2001; Horne \& Reyner 1996; Reyner \& Horne 2002). The evidence relating to the alerting effects of caffeine and naps is so well supported, that it has been incorporated into the UK Highway Code, under 'Fitness to Drive' (Rule 91; Department for Transport 2019b).

Popular strategies such as opening a window, turning on the radio, and taking a break, can be ineffective at reducing sleepiness for extended time periods (Horne \& Reyner 1996; Schwarz et al. 2012). Despite this, opening a window/turning on the air conditioner and listening to music are utilised more so than effective roadside countermeasures (Anund et al. 2008) or alongside effective strategies (Nordbakke \& Sagberg 2007; Pylkkönen et al. 2015). However, the majority of evidence relating to both effective and ineffective countermeasures comes from passenger car drivers, and in most cases, controlled experiments. Controlled studies are beneficial, as the control of potential confounding factors is necessary to be sure that any effect is real; however, the limitation is that they do not indicate how countermeasures are applied in the real world. This is important, because there is suggestion 
that within public transport drivers, ineffective strategies are commonly used, for example, within a sample of tram drivers (Onninen et al. 2020). Qualitative analysis of train driver focus group data indicates drivers may frequently use countermeasures, such as cold air, talking to people, driving slower, and kneeling, to manage fatigue both before experiencing it, e.g., before duty, and when experiencing it at work (Filtness \& Naweed et al. 2017). Although bus drivers were not the focus of these studies, train and tram drivers experience much of the same working environment as bus drivers, for example, typically being the sole driver on duty, being confined to a cab, and being required to follow schedules. It is, therefore, likely that potentially ineffective countermeasures are also being used by bus drivers, and this is the focus of the present study.

It is important to understand how sleepiness is currently being managed by bus drivers and what products and strategies are being used to counteract sleepiness. As shift workers, it is probable that city bus drivers experience sleepiness; however, there is a lack of research into the strategies and methods that they potentially use to manage it. This qualitative study investigates how city bus drivers individually manage and counteract sleepiness on a day-to-day basis.

\section{Materials and methods}

\section{Study design}

To understand the experiences, views, and opinions of the bus drivers in relation to sleepiness, data were collected using qualitative research techniques. Focus groups were conducted with a sample of city bus drivers, conducted at sites of each of the main operators in London. A standard protocol of prompts and discussion points was utilised, ensuring all focus groups were conducted in similar format. When talking to the drivers, the word "fatigue" was used, as this is the commonly used industry term. However, at the beginning of 
each focus group, this was defined to ensure sleepiness-related fatigue, rather than taskrelated fatigue, was the focus. The main topics for the discussion prompts were occurrence and experience of fatigue, causes and consequences of fatigue, strategies for how fatigue was managed, workplace culture surrounding fatigue, sleep and fatigue outside work, shift patterns and overtime, and stress and pressure. Two facilitators attended each group, with one researcher being consistent for all groups. The current analysis focuses on the specific topic of individual countermeasure use. Analysis of broader themes of driver fatigue and sleepiness are reported elsewhere (Filtness et al. 2019).

\section{Participants}

The participants were London city bus drivers who were invited to participate by the operators that employed them. In total, 62 drivers participated, 49 males and 13 females. The largest proportion of the drivers were between $45-54$ y of age (35.5\%), with $26.2 \%$ of drivers between 54-65 y, 21\% of drivers between 35-44 y, and 16.9\% of drivers between 25-34 y of age. The proportion of female participants and range of ages included in the study is comparable to London and UK bus drivers, overall (Department for Transport 2019a). The mean experience of bus driving was $13.3 \mathrm{y}$. The only inclusion criterion was that the drivers had been driving buses for at least $1 \mathrm{y}$.

\section{Procedure}

The study was funded by Transport for London and received University ethical approval from Loughborough University in line with international standards. Nine semi-structured focus group meetings were conducted, exploring fatigue and sleepiness and use of individual sleepiness countermeasures. Operators were initially contacted to identify suitable depots and garages for conducting the focus groups, and a relevant contact at each of the nine sites. Drivers were then invited to attend the discussion in groups of six to eight. The focus groups 
were conducted within the organizations to facilitate access and allow scheduling into work rosters. However, participation was voluntary, and all participants gave informed written consent. Data were collected during October and November 2018.

At the beginning of each focus group, drivers were presented with an information sheet and consent form. Basic demographic information was collected through a brief survey that was completed before the start of each focus group discussion session. Each group was attended by two researchers. A protocol of prompts was developed to facilitate discussion and ensure continuity between groups. Drivers were encouraged to view the discussion as informal and to feel comfortable to express their views and opinions. Table 1 provides an overview of the prompts and questions used for the focus groups.

Table 1. Overview of prompts and questions

\begin{tabular}{ll}
\hline Topic & Example question \\
\hline Introduction & How long have you been driving buses? \\
Experience of fatigue & Could you describe a situation where you or anyone you know \\
& has suffered from driver fatigue during work? \\
Causes and consequences of & How is your driving affected when you feel fatigued / sleepy? \\
fatigue & What do you do if you feel fatigued / sleepy? \\
Strategies to manage fatigue & Could you describe how you communicate with your employer \\
Workplace culture & or supervisor if you were fatigued / sleepy at work? \\
Sleep and fatigue outside work & What factors influence how much you would sleep when not at \\
& work? \\
Shift patterns and overtime & Are there any specific times of the day, situations, or points in a \\
& shift / shift pattern when you are most likely to feel fatigued /
\end{tabular}




\section{sleepy?}

Stress and pressure

What aspects of the job are most stressful for you? Do these link

to feelings of fatigue?

\section{Data analysis}

The focus groups were audio recorded, with a total time of $682 \mathrm{~min}$, and transcribed anonymously verbatim. The transcripts were analyzed in NVivo 12.0, a qualitative data analysis software program. Thematic analysis was conducted, following the guidelines outlined by Braun and Clarke (2006). This method of analysis was chosen as it allows the themes to develop from the participants' own narrative. During the analysis, inductive thematic analysis was used, where the themes are driven by the data, rather than being theoretically driven by predetermined themes.

In the first instance, all the data relating to the use of individual sleepiness countermeasure strategies to manage fatigue were identified as units of information that addressed the research aims. This was achieved by a detailed review of the transcripts. Discussion relating to countermeasure use was isolated and sections of relevant text from the first mention of the topic until a different topic was mentioned were selected and put into a new transcript for analysis. While most of this text came from the discussion topic 'strategies to manage fatigue', it was not limited to this discussion point. If there were relevant mentions in response to other topics and prompts, these were also included. Countermeasure use was mentioned at all focus groups; in total, nine new transcripts were created. These transcripts were then read through, with a bottom up coding approach. Once a complete list of initial codes had been created, the transcripts were re-analyzed with all codes being applied (where appropriate) to each transcript. An independent second coder reviewed a selection of the 
coding, and the codes were discussed. Following this, the codes were grouped into categories, with similar codes combined to develop themes. Relevant extracts were identified to support each of the themes. Finally, the themes and subthemes were reviewed and refined.

\section{Results}

The use of individual countermeasures to sleepiness was discussed in all nine focus groups. Thematic analysis identified two main themes: (1) strategies used to counteract sleepiness, and (2) barriers to individual countermeasure use. Within each theme, several subthemes were identified, four subthemes and five subthemes, respectively. Table 2 provides a summary of the main themes and subthemes.

Table 2. Main themes and subthemes identified by the thematic analysis

Main themes $\quad$ Sub themes

1. Strategies used to counteract sleepiness $(n=9) \quad 1.1$ Effective strategies $(n=9)$

1.2 Ineffective strategies $(n=9)$

1.3 During duty use $(\mathrm{n}=9)$

1.4 Off duty use $(\mathrm{n}=8)$

2. Barriers to individual countermeasure use $(n=9)$

2.1 Workplace restrictions $(\mathrm{n}=9)$

2.2 Facilities $(\mathrm{n}=9)$

2.3 Breaks/turnaround time $(\mathrm{n}=9)$

2.4 Education $(n=9)$

2.5 Job of a bus driver $(\mathrm{n}=9)$

Note. $\mathrm{n}=$ number of focus groups theme appeared in, out of a total of 9 . 


\section{Strategies used to counteract sleepiness}

This theme details the strategies that are used by the drivers to counteract their sleepiness. Within this main theme, four subthemes were identified. The drivers discussed managing sleepiness in relation to effective and ineffective strategies -- definition defined by previous literature stating those strategies which have or have not shown beneficial effects of reducing sleepiness -- and strategies used both on duty and off duty. The subthemes below have been described separately; although, there is some overlap between them.

\section{Effective strategies}

This subtheme highlighted the strategies used by drivers that have been shown to be effective at reducing objective sleepiness, e.g., use of caffeine and/or naps, and appeared in all nine focus groups. When discussing how drivers managed their sleepiness, one of the most frequently discussed strategies was the use of caffeine, which was mentioned in all nine of the focus groups. For example: "Yeah, coffee, strong coffees. I mean the amount of coffees drivers drink is unbelievable". Other sources of caffeine were also mentioned, e.g., use of energy drinks and pro-plus tablets. However, several drivers discussed being wary of consuming energy drinks due to the associated negative health consequences, or the fact they were "too sugary". Alongside the use of caffeine, napping was also discussed within all the focus groups as a strategy to counteract sleepiness. This strategy, often referred to as a 'power nap', appeared to be used if the drivers felt they had enough time, and usually occurred in the bus at the end of a route: "Sometimes, at the other end I just put my head down and sleep, a power nap". Several drivers also reported napping during their breaks, often in the canteen as for the majority, if not all, of the drivers, there were no designated areas available to them specifically for napping.

\section{Ineffective strategies}


The subtheme of ineffective strategies highlights the methods used by the drivers which, in terms of alleviating or reducing sleepiness, have been deemed ineffective, as defined in the introduction. Ineffective strategies were discussed by drivers in all nine focus groups. Most of the drivers reported opening a window for fresh air, e.g.,"... to get fresh air to keep us alert, because one other thing when you're tired and fatigued, you open your window and you get a bit of fresh air, that sometimes, blowing wind wakes you." However, there was an acknowledgement by a several of the drivers that this did not help to counteract sleepiness, e.g., R2: “Open the window, because you can't stop the bus and get out and have a stretch, you know, you just have to open the window for that little bit." R1: "Even if I'm tired opening the window doesn't help you." R2: "Oh it helps me."

Other strategies that were discussed frequently by the drivers were to talk or sing to themselves, drink water, interact with passengers, or to walk around the bus and stretch, with the emphasis being on just doing something, e.g., R2: “What I do sometimes, I get out to do the mirrors. There's nothing wrong with my mirror." R4: "Yeah, that's what I'm saying, but just by getting out of that cab and doing something, you're more alert." R2: "That will keep me going for another twenty minutes." The final strategy that was mentioned by several drivers was use of sugar. For example, when discussing ways to manage sleepiness, drivers would mention sugar in relation to alleviating sleepiness: "If you're tired and if you need sugar relief."

\section{During duty use}

Strategies used by drivers during duty -- between clock in and clock out, including breaks -were highlighted in this subtheme, which appeared in nine focus groups. In terms of managing sleepiness, most strategies discussed were in relation to those used during a driver's duty period, rather than before or after duty. Drivers reported a range of strategies in 
all focus groups, including the use of coffee, sugar, water, fresh air, stretching, talking, and napping. Importantly, it appeared that the choice of strategy used during duty was dictated by other subthemes, e.g., time and location of breaks, available facilities, and restrictions of the workplace. One driver reported: "I agree with coffee, but you can't easily get coffee" and another mentioned: "Open the window, put the air-con on, anything, it's stupid. Do you know, I even try and talk to the passengers just to keep myself on the ball?"

Off duty use

In eight of the nine focus groups, drivers discussed certain strategies they employed to manage their sleepiness, which were used outside of their shift or duty period. For example, several drivers mentioned obtaining adequate sleep before duty: "Sleep as much as you can". A few drivers mentioned exercise in relation to managing their fatigue and sleepiness, attempting to walk, cycle, or visit the gym, which made the drivers feel better during their shifts: "Sometimes I use my bike coming into work. It's like ten miles one way. I feel much better after that." However, it was also evident from the discussions that many drivers felt unable to use measures to counteract sleepiness off duty, due to time pressure. Several drivers commented that the time between shifts was short, especially when commuting and family life were taken into consideration. For example, when asked about napping at home before work, drivers said, e.g., R2: “Well, we haven't got the time because if you've got 10 hours between duties, sometimes you have 10, 11, okay, you go home, you've for the kids, you've got your wife." R3: "Traveling time." R2: "Traveling time. Then you sleep for seven, eight hours, that's it. Then you wake up, just take a shower."

\section{Barriers to individual countermeasure use}

This theme highlights the barriers faced by the bus drivers in using sleepiness countermeasures. The theme was divided into five subthemes that are described below and 
summarized in Table 2. Although each of the subthemes are separately described, it is important to note that most of them will have an effect or influence upon the others.

\section{Workplace restrictions}

From the discussions in all nine of the focus groups, it was clear that certain features of the work environment acted as a barrier to the drivers of managing their sleepiness. Firstly, drivers spend most of their shift confined within the cab of a bus. For health and safety reasons, they are not allowed to drink in the cab, and are only able to drink at the stand or "Only if you're stationary with your handbrake on." Running and stand times can also influence whether drivers have time to have a coffee, have a power nap, or can go to the toilet, further restricting their options. It appeared from the all the discussions that the ineffective sleepiness countermeasures that are used by bus drivers are most often the only strategies that are available to them during their shift.

\section{Facilities}

In terms of barriers to countermeasure use, the subtheme of facilities was an important topic, covering several aspects. This subtheme was discussed in all the focus groups, with many drivers mentioning the lack of available facilities as an issue. Firstly, it was evident from the discussions that depending on the route, the bus drivers may not have access to any facilities: “... Because some of the routes you do on one end there'll be proper toilets and others, they're nothing at all. And especially if you're doing lates, there's nowhere to go." Drivers frequently reported having limited access to toilets, which impacted their choice of strategy to manage sleepiness. In terms of canteens, the availability, again, appeared to be determined by route or by the timing of the shift. Several drivers reported that their depot did not have a canteen, and others reported that they did, but it was only open at certain times and on certain days. It was also evident that the none of the drivers had rest areas designed for napping, with 
several drivers reporting naps taking place in the canteen, e.g., R3: "Well that's on the duties, that we're probably on now, the spreads, we see a lot of the guys up in the canteen who are sleeping”. R2: "They are all lying down and sleeping."

\section{Breaks/ turnaround time}

The concept of breaks and turnaround time in relation to managing fatigue and sleepiness was discussed throughout the nine focus groups and was an important subject for the drivers. Turnaround time referred to the time a driver has at the end of their route, before heading back out again. This would usually be at a bus stand or stop and can be impacted by traffic and running times. Although the drivers appeared to understand that this turnaround time was not a designated break, it was clear from the discussions that this time was important to them and that when circumstances reduced this time, they felt it impacted their fatigue and sleepiness. In many of the focus groups, several drivers discussed that they make use of this turnaround time to manage their sleepiness, e.g., "That's what people do. They get to the other end, put their head down, set their alarm, try and get that ten/fifteen minutes." Drivers also referred to this time as recovery and rest time before heading back out again. However, it was clear that these 10 or 15 min can be reduced or missed completely depending on traffic and running times.

Many drivers stressed the importance of breaks to rest, recover, and relax. Several drivers reported napping during the break, typically in the canteen or chairs in the common area, and this is where drivers would have more of an opportunity to eat and have coffee. However, it was evident that the location of their break depended on their route, and several drivers reported a lack of facilities at break locations: "There's no toilets, we have to have our breaks standing on a bus stop. No canteens or nothing." Time pressure was also associated 
with the discussion of breaks, with increased traffic and delayed running times reducing break time, which drivers would not necessarily gain back.

\section{Education}

Driver education relating to managing fatigue and sleepiness is highlighted in this subtheme, which was apparent in all the focus groups. There appeared to be a difference in opinion amongst the drivers as to whether they receive training, education, advice, or support in this area. Several drivers reported that they had not received any education: "This is the first time we're actually talking about it, nobody says anything about it". However, some drivers reported seeing posters relating to fatigue and sleepiness, or the creation of discussion groups to tackle the issue. One driver reported the introduction of an app but was not convinced it would provide the right information. It was also evident from the discussions that many of the drivers were not educated in effective strategies to manage their sleepiness, which was clear from the frequent reporting of ineffective countermeasures, such as sugar, water, or fresh air.

\section{Job of a bus driver}

Finally, the job of being a bus driver as a barrier to countermeasure use developed as a subtheme from the discussions of all the focus groups. It was evident that certain aspects of the job restricted and impeded the drivers in managing their sleepiness. For example, a bus driver faces several pressures from running times and passengers that would make it difficult to stop the bus due to sleepiness: "Unfortunately, it's different to being in the car. In the car you can stop and get out and walk. On a bus, you can't." In addition, as presented in a previous subtheme, many drivers reported opening a window to manage their sleepiness. However, it was also mentioned by several drivers that there was a general concern about opening windows, due to potential threats and violence bus drivers may face, e.g., R3: "We're scared of opening up our windows to get fresh air to keep us alert, because one other 
thing when you're tried and fatigued, you open your window and you get a bit of fresh air, that sometimes, blowing wind wakes you. But because of all these chemical attacks, and people throwing stuff at the window, we are scared." R2: "I don't want to open my window." R6: "Yeah, because cyclists, you don't know what, sometimes they are angry at drivers, so they might throw something."

\section{Discussion}

The current study explored the ways city bus drivers manage their fatigue and sleepiness during their shift. To our knowledge, this research is some of the first to explore the use of individual countermeasures against sleepiness within a sample of bus drivers. As a population of shift workers, bus drivers are an under-researched group, despite being at risk of sleepiness through shift work-related factors and having the safety critical task of driving a bus with passengers. This qualitative study demonstrated that city bus drivers used a variety of strategies to manage their sleepiness, however, importantly, they faced several barriers to effective countermeasure use, many of which were directly associated with workplace constraints.

Although previous work has shown the effectiveness of countermeasures in alleviating sleepiness and reducing the likelihood of sleep-related road crashes (Cummings et al. 2001), the current work demonstrates that certain workplace restrictions impact the way bus drivers manage their sleepiness, influencing the use, choice, and availability of countermeasures. Firstly, it was evident that the occupation of being a bus driver impacted countermeasure use. Drivers spend their shift confined in a cab, adhering to running times, and a particular route, which collectively impacts their options for managing sleepiness. Bus drivers are unable to stop and take a break if needed, unlike non-professional and some other professional drivers. For example, long distance truck drivers have been found to use both 
napping and rest breaks as countermeasures to sleepiness when driving (Pylkkönen et al. 2015). In terms of public transport, increased sleepiness or reduced fitness to drive increases the accident and safety risk to the driver, but also to the passengers and pedestrians. Therefore, continuing to drive when sleepy is an important concern for bus driver operators.

Running times create time pressure, impinging on break and turnaround times. This is an important issue discussed often by the drivers, as they stated the importance of utilizing this time to rest and recover. If drivers see this as time to implement strategies to manage their sleepiness, and rely on this time, this could cause an issue if other factors, ,e.g., traffic, reduces this time. Previous work has identified time pressure to be an issue for bus drivers, often generated by narrow delay margins that can restrict turnaround time and breaks, increasing drivers' overall stress levels (Biggs et al. 2009).

It was clear that the route the worked is also an important influence on countermeasure use, dictating where drivers' breaks are located and what facilities are available to them. Many drivers reported that this results in being unable to utilize effective strategies to reduce sleepiness due to limited toilet facilities or ease of purchasing or drinking coffee/caffeine beverages. Research on passenger car drivers has shown crash reduction in those individuals who use rest stops or service stations (Cummings et al. 2001); however, this will also be influenced by the route bus drivers are driving and availability of rest facilities, an important workplace consideration that is out of control of the bus drivers themselves. This may also explain, in part, why some bus drivers reported using sugar to manage their sleepiness, as sugar in the form of a chocolate bar or sweets can easily be carried in a pocket or bag and possibly be easier to eat during shifts or when driving. The drivers are also reliant on the facilities provided by their company. For example, several drivers reported napping during their breaks as an effective strategy to alleviate sleepiness and an approach that is supported by controlled experimental evidence (Horne \& Reyner 1996; Watling et al. 2014). 
However, if a driver wanted to nap, they reported using the canteen tables and common area chairs, or napping in the cab of the bus, due to the lack of quiet sleeping facilities. Access to adequate facilities is an important workplace consideration, since bus drivers sleeping in inappropriate places between shifts has previously been shown to detrimentally impact sleep quality (Deza-Becerra et al. 2017).

A further restriction was education. Education relating to the causes and consequences of fatigue in association with shift work is often advocated as an important countermeasure to reduce fatigue and sleepiness, with previous bus driver research highlighting the need for educational interventions (Deza-Becerra et al. 2017). There appeared to be a difference in opinion from the drivers as to whether they received education and training about managing sleepiness. Although education alone is not enough to mitigate against fatigue (Pylkkönen et al. 2018), educating drivers on ways to manage shift work is an important step, particularly in relation to effective countermeasure use. Education relating to the effective use of sleepiness countermeasures is not solely an issue for bus drivers or shift workers. Research indicates that this is a wider problem, as private passenger car drivers (Anund et al. 2008) and public transport drivers (Filtness \& Naweed 2017; Onninen et al. 2020) also utilize ineffective strategies to alleviate sleepiness when driving. Therefore, many people may benefit from education aimed at informing drivers about what is and is not effective in reducing sleepiness when driving.

Both the use of effective and ineffective strategies to counteract sleepiness and fatigue was reported by the bus drivers. The use of coffee was frequently reported by the drivers, using it to increase alertness during their shifts. Using forms of caffeine to alleviate sleepiness is a well-known strategy, shown to effectively increase alertness and improve performance (De Valck \& Cluydts 2001; Horne \& Reyner, 1996; Reyner \& Horne 2002), and typically quite easy to obtain. However, it was apparent from discussions that, although the 
drivers understand the alerting properties of caffeine, they were sometimes reluctant or unable to consume it due to the lack of facilities and time pressures. This may, in part, explain why drivers chose to use ineffective sleepiness countermeasures. Within the focus groups, drivers frequently reported the use of ineffective measures, including opening a window, stretching, singing, talking, and using forms of sugar to alleviate sleepiness. This corresponds with previous driving research that shows certain ineffective sleepiness countermeasures are utilized more than (Anund et al. 2008) or alongside (Nordbakke \& Sagberg 2007; Pylkkönen et al. 2015) effective roadside measures to counteract sleepiness. It may be that drivers believe that these measures are counteracting their sleepiness and making them feel more alert. However, the barriers mentioned during the focus groups relating to drinking coffee and lack of opportunity or facility to nap would likely lead drivers away from effective countermeasures into other strategies, such as sugar snacks, which are less influenced by workplace constraints. Either way, for those drivers that are using and relying on ineffective strategies to counteract sleepiness, this could have severe safety implications, as driver sleepiness is associated with increased crash risk (Bioulac et al. 2017).

When discussing sleepiness countermeasures, for the most part, drivers focused on how they managed their sleepiness during their shift, between clocking in and clocking out, rather than before or following work. This may be because bus drivers feel sleepiness during their shift and when driving is an important issue and needs to be managed. Other research with bus drivers (Deza-Becerra et al. 2017) and truck drivers (Pylkkönen et al. 2015) has also identified that work factors influenced sleep, potentially leading to increased sleepiness. However, drivers may have preferred to emphasize work rather than personal responsibility, if they thought any findings would be reported to employers. Several drivers mentioned that time following shifts was short, especially to commute home, sleep, eat, socialize with family, and then return to work. Therefore, drivers may not have time for additional 
sleepiness management strategies outside their work hours, such as napping. Unrealistic scheduling has been shown to be a contributing factor to fatigue and sleepiness within bus drivers. Extended commute times, long shifts, and short time between shifts can result in reduced sleep opportunities, which can accumulate, increasing the risk of sleepiness (Biggs et al. 2009).

Although this research focused specifically on the use of individual sleepiness countermeasures, it is important to recognize that individual countermeasures are only one component in the sleepiness management of shift workers. Workplace countermeasures also have an important role to play in fatigue risk management (FRM) systems and can directly and indirectly influence individual countermeasure use. When making decisions about companywide FRM, it is important to understand what is happening within the workplace at an employee level. For example, a FRM program may include driver education, containing topics such as sleepiness management during shifts, and recommendations for caffeine and napping. If drivers have limited understanding relating to effective measures to counteract sleepiness, drivers may continue to use ineffective strategies to mitigate their sleepiness. Education can be beneficial if the main barrier to effective countermeasure use is that drivers do not have the correct knowledge. However, education programs will be ineffective at reducing fatigue and sleepiness if other workplace barriers are still in place and drivers do not have the facilities or means to utilize these strategies (Pylkkönen et al. 2018). Deciding on appropriate countermeasure use involves a complex chain of factors. Alongside knowledge about effective strategies and appropriate facilities, individuals also need to be able to recognize when they are sleepy and be motivated to act on those feelings (Anund et al. 2015). The final stage of the chain, and one relevant to this research, is that drivers are not prevented to act, for example by workplace barriers and restrictions. This, therefore, highlights the 
complexity of addressing sleepiness within professional settings and implementing effective FRM programs.

Sleepiness countermeasures can be utilized to reduce the likelihood of having a sleeprelated crash (Cummings et al. 2001) and to alleviate signs and symptoms of sleepiness during shift work. The results of this research indicate that, importantly, workplace restrictions influence the use, choice, and availability of sleepiness countermeasures. As public transport drivers, bus drivers face many of the same issues shift workers face in terms of managing rest, shift patterns, working unsociable hours, juggling responsibilities, and commuting within rest periods. However, bus drivers also experience several specific workplace considerations that can impact sleepiness and individual countermeasure use. It is evident from this research that aspects of the job of bus driver restricted and impeded drivers in managing their sleepiness. To address this issue within the bus driver population, these workplace constraints need to be considered in relation to company FRM programs. Optimal FRM policies and procedures can be implemented; however, these will not be effective if there is no understanding of how sleepiness and fatigue are managed on a daily basis, or if there is a mismatch in knowledge and expectation between employers and employees. To effectively mitigate fatigue and sleepiness during shifts, drivers need to be educated in the use of effective countermeasures, and, importantly, have the ability and opportunity to implement that knowledge.

\section{Limitations}

As with all research, there were some study limitations. Firstly, the research was conducted solely with London city bus drivers, who experience a somewhat unique transport system that may limit the generalizability of findings. However, this is also important, as London experiences high volumes of traffic and utilizes $24 \mathrm{~h}$ operations; therefore, the experience of 
the drivers may be viewed as a "worst case scenario". Traffic and shift work are also typical of city bus driving; so, the findings are relevant to other city drivers. Representation from a wide variety of operators was a priority when designing the study. This was achieved with nine out of 10 operators being represented. Although the overall sample size is a small proportion of bus drivers, it is inclusive of all work practices within London. However, drivers who worked predominantly night shifts were not well represented $(n=6)$, as the focus groups were conducted during the day when most night shift drivers were not available. Although the use of individual countermeasures to sleepiness was not the primary aim of the discussions, it was discussed in every focus group. Therefore, any mention or emphasis of individual countermeasure use means it was important to the person discussing it. However, despite emphasizing that the focus was on sleepiness-related fatigue, it is possible that when drivers were discussing mitigation strategies, they also discussed strategies to manage taskrelated fatigue. Finally, as the original prompts were broad in nature, this allowed discussions to be led by the drivers themselves. While this provided freedom for drivers to discuss issues important to them, the management of potential key sleepiness-related issues, such as sleep disorders or sleep disordered breathing, were not addressed within this research. As this potentially is an important issue within shift working groups, which needs management at both an organizational and individual level, further research may be needed to explore this topic.

\section{Conclusion}

Bus drivers perform an important safety critical role and are at risk of increased sleepiness and shift work related factors. It is important that drivers have access to, and are aware of the effectiveness of, measures in order to manage sleepiness during shift work. It is also vital that the actions of drivers and shift workers are better understood in the planning of organizational countermeasures. 
This qualitative research is some of the first to investigate the use of sleepiness countermeasures within a sample of city bus drivers by conducting focus groups to explore drivers' views and opinions of sleepiness and sleepiness alleviating strategies within a professional setting. Thematic analysis resulted in two main themes: (1) strategies used to counteract sleepiness, and (2) barriers to individual countermeasure use. It was clear from the discussions that both effective and ineffective countermeasures were used by the drivers, but importantly, workplace restrictions were an influencing factor in countermeasure use, availability, and choice. The use of ineffective sleepiness countermeasures is a concern, as driving is a safety critical task, and relying on ineffective strategies to alleviate sleepiness could have serious consequences. To reduce the use of ineffective countermeasures, good education is needed for drivers and operators at all levels. Drivers also need to be empowered to enact the knowledge gained from education. Further research should focus on how operators could address workplace constraints that might restrict the use of effective measures or facilitate the use of ineffective measures. It is also important that implementation of organizational FRM considers individual countermeasure use and associated workplace constraints in order to be effective.

\section{Acknowledgements}

The authors would like to thank the participants for their time and their contribution to this research. The authors would also like to thank Transport for London (TfL) for their funding and support. The authors would like to thank Dr Sally Maynard for her advice and assistance with coding. Finally, the authors gratefully acknowledge Dr Anna Anund, Karl Miller, Dr Sally Maynard, Dr Anna Sjörs Dahlman and Jonas Ihlström, who were collaborators on this research project.

Declaration of interest: none. 


\section{References}

1. Åkerstedt, T., Hallvig, D., Anund, A., Fors, C., Schwarz, J., Kecklund, G. 2013. Having to stop driving at night because of dangerous sleepiness-awareness, physiology and behaviour. J Sleep Res. 22(4): 380-388. doi:10.1111/jsr.12042.

2. Anund, A., Kecklund, G., Peters, B., Åkerstedt, T. 2008. Driver sleepiness and individual differences in preferences for countermeasures. J Sleep Res. 17(1): 16-22. doi:10.1111/j.1365-2869.2008.00633.x.

3. Anund, A., Fors, C., Kecklund, G., Leeuwen, W. V., Åkerstedt, T. 2015. Countermeasures for fatigue in transportation: a review of existing methods for drivers on road, rail, sea and in aviation. Linköping: Swedish National Road and Transport Research Institute (VTI).

4. Anund, A., Ihlström, J., Fors, C., Kecklund, G., Filtness, A. 2016. Factors associated with self reported driver sleepiness and incidents in city bus drivers. Ind Health. 54(4): 337-346. doi:10.2486/indhealth.2015-0217.

5. Anund, A., Ahlström, C., Fors, C., Åkerstedt, T. 2018. Are professional drivers less sleepy than non-professional drivers?. Scand J Work Environ Health. 44(1): 88- 95. doi:10.5271/sjweh.3677.

6. Biggs, H., Dingsdag, D., Stenson, N. 2009. Fatigue factors affecting metropolitan bus drivers: A qualitative investigation. Work. 32(1): 5-10. doi:10.3233/WOR-2009-0810.

7. Bioulac, S., Franchi, J. A. M., Arnaud, M., Sagaspe, P., Moore, N., Salvo, F., Philip, P. 2017. Risk of motor vehicle accidents related to sleepiness at the wheel: a systematic review and metaanalysis. Sleep. 40(10). doi:10.1093/sleep/zsx134.

8. Braun V, Clarke V. 2006. Using thematic analysis in psychology. Qual Res Psychol. 3(2):77-101. doi:10.1191/1478088706qp063oa. 
9. Chaiard, J., Deeluea, J., Suksatit, B., Songkham, W. 2019. Factors associated with sleep quality of Thai intercity bus drivers. Ind Health. 57(5): 596-603. doi:10.2486/indhealth.2018-0168.

10. Connor, J., Norton, R., Ameratunga, S., Robinson, E., Civil, I., Dunn, R., Bailey, J., Jackson, R. 2002. Driver sleepiness and risk of serious injury to car occupants: population-based case control study. Bmj. 324(7346): 1125. doi:10.1136/bmj.324.7346.1125.

11. Cummings, P., Koepsell, T. D., Moffat, J. M., Rivara, F. P. 2001. Drowsiness, counter-measures to drowsiness, and the risk of a motor vehicle crash. Inj Prev. 7(3): 194-199. doi:10.1136/ip.7.3.194.

12. Dement, W. C., Carskadon, M. A. 1982. Current perspectives on daytime sleepiness: the issues. Sleep: J Sleep Res Sleep Med. 5(Suppl 2): 56-66. doi:10.1093/sleep/5.S2.S56.

13. Department for Transport. 2019a. Annual bus statistics: England 2018/19. London, UK: The Stationery Office. Retrieved from:

https://www.gov.uk/government/statistics/annual-bus-statistics-year-ending-march$\underline{2019}$

14. Department for Transport. 2019b. The highway code. London, UK: The Stationery Office. Retrieved from: https://www.gov.uk/guidance/the-highway-code

15. De Valck, E., Cluydts, R. 2001. Slow-release caffeine as a countermeasure to driver sleepiness induced by partial sleep deprivation. J Sleep Res. 10(3): 203-209. doi:10.1046/j.1365-2869.2001.00260.x.

16. Deza-Becerra, F., de Castro, J. R., Gonzales-Gonzales, C., León-Jiménez, F. E., Osada-Liy, J., RosalesMayor, E. 2017. Sleep habits, fatigue, and sleepiness in 
Chiclayo-Peru's bus drivers. Sleep Breath. 21(3): 745-749. doi:10.1007/s11325-017$1502-9$

17. Filtness, A. J., Anund, A., Maynard, S., Miller, K., Pilkington-Cheney, F., Dahlman, A., \& Ihlström, J. 2019. Bus Driver Fatigue. Report to Transport for London.

18. Filtness, A. J., Naweed, A. 2017. Causes, consequences and countermeasures to driver fatigue in the rail industry: The train driver perspective. Appl. Ergon 60: 12-21. doi:10.1016/j.apergo.2016.10.009

19. Friswell, R., Williamson, A. 2008. Exploratory study of fatigue in light and short haul transport drivers in NSW, Australia. Accid Anal Prev 40(1): 410-417. doi:10.1016/j.aap.2007.07.009.

20. Gander, P., Hartley, L., Powell, D., Cabon, P., Hitchcock, E., Mills, A., Popkin, S. 2011. Fatigue risk management: Organizational factors at the regulatory and industry/company level. Accid Anal Prev. 43(2): 573-590. doi:10.1016/j.aap.2009.11.007.

21. Horne, J. A., Reyner, L. A. 1995. Sleep related vehicle accidents. Bmj. 310(6979): 565-567. doi:10.1136/bmj.310.6979.565.

22. Horne, J. A., Reyner, L. A. 1996. Counteracting driver sleepiness: effects of napping, caffeine, and placebo. Psychophysiology. 33(3): 306-309. doi:10.1111/j.14698986.1996.tb00428.x.

23. May, J. F., Baldwin, C. L. 2009. Driver fatigue: The importance of identifying causal factors of fatigue when considering detection and countermeasure technologies. Transp Res Part F Traffic Psychol Behav. 12(3): 218-224. doi:10.1016/j.trf.2008.11.005. 
24. Miller, K. A., Filtness, A. J., Anund, A., Maynard, S. E., Pilkington-Cheney, F. (2020). Contributory factors to sleepiness amongst London bus drivers. Transp Res Part F Traffic Psychol Behav. 73: 415-424. doi: 10.1016/j.trf.2020.07.012

25. Nordbakke, S., Sagberg, F. 2007. Sleepy at the wheel: Knowledge, symptoms and behaviour among car drivers. Transp Res Part F Traffic Psychol Behav. 10(1): 1-10. doi:10.1016/j.trf.2006.03.003.

26. Onninen, J., Hakola, T., Puttonen, S., Tolvanen, A., Virkkala, J., Sallinen, M. 2020. Sleep and sleepiness in shift-working tram drivers. Appl. Ergon 88: 103153. doi:10.1016/j.apergo.2020.103153

27. Öz, B., Özkan, T., Lajunen, T. 2010. Professional and non-professional drivers’ stress reactions and risky driving. Transp Res Part F Traffic Psychol Behav. 13(1): 32- 40. doi:10.1016/j.trf.2009.10.001.

28. Philip, P., Chaufton, C., Orriols, L., Lagarde, E., Amoros, E., Laumon, B., Åkerstedt, T., Taillard, J., Sagaspe, P. 2014. Complaints of poor sleep and risk of traffic accidents: a population-based case-control study. PloS one. 9(12): e114102. doi:10.1371/journal.pone.0114102.

29. Pylkkönen, M., Sihvola, M., Hyvärinen, H. K., Puttonen, S., Hublin, C., Sallinen, M. 2015. Sleepiness, sleep, and use of sleepiness countermeasures in shift-working longhaul truck drivers. Accid Anal Prev. 80: 201-210. doi:10.1016/j.aap.2015.03.031.

30. Pylkkönen, M., Tolvanen, A., Hublin, C., Kaartinen, J., Karhula, K., Puttonen, S., Sihvola, M., Sallinen, M. 2018. Effects of alertness management training on sleepiness among long-haul truck drivers: A randomized controlled trial. Accid Anal Prev. 121: 301-313. doi:10.1016/j.aap.2018.05.008. 
31. Reyner, L. A., Horne, J. A. 2002. Efficacy of a 'functional energy drink' in counteracting driver sleepiness. Physiol Behav. 75(3): 331-335. doi:10.1016/S00319384(01)00669-2.

32. Schwarz, J. F., Ingre, M., Fors, C., Anund, A., Kecklund, G., Taillard, J., Phillip, P., Åkerstedt, T. 2012. In-car countermeasures open window and music revisited on the real road: popular but hardly effective against driver sleepiness. J Sleep Res. 21(5): 595-599. doi:10.1111/j.1365-2869.2012.01009.x.

33. Vennelle, M., Engleman, H. M., Douglas, N. J. 2010. Sleepiness and sleep-related accidents in commercial bus drivers. Sleep Breath. 14(1): 39-42. doi:10.1007/s11325009-0277-z.

34. Wagstaff, A. S., Lie, J. A. S. 2011. Shift and night work and long working hours-a systematic review of safety implications. Scand J Work Environ Health. 37(3): 173185. doi:10.5271/sjweh.3146.

35. Watling, C. N., Smith, S. S., Horswill, M. S. 2014. Stop and revive? The effectiveness of nap and active rest breaks for reducing driver sleepiness. Psychophysiology. 51(11): 1131-1138. doi:10.1111/psyp.12256. 